\title{
Promoting Learning-Focused Teaching Through a Project-Based Faculty Development Program
}

\author{
Susanna Calkins, Greg Light \\ Northwestern University
}

This chapter describes how we incorporated project-based learning into a yearlong faculty development program at a research-intensive private university located in the Midwest. This inquiry-based approach fosters critical reflection on teaching and promotes learner-focused teaching in a manner that encourages deeper student approaches to learning. We use case studies, drawn from critical accounts of faculty projects, to illustrate a model that depicts how faculty understand improvement in their teaching and to identify key program elements that facilitated the adoption of learning-focused teaching practices by our participants.

or many faculty, finding the space and time to critically reflect on their
teaching —and to consider how it relates to student learning-is a marginalized endeavor, especially when outweighed by demands of research, tenure, and promotion (Boice, 1992; Brew, 2003; Hattie \& Marsh, 1996; Mullen \& Forbes, 2000; Wolverton, 1998). Yet critical reflection is essential for developing sound teaching (Palmer, 1998), fostering professional development (Schön, 1983), and enhancing student learning (Light \& Cox, 2001; McAlpine \& Weston, 2000).

Since 1999, we have offered early-career faculty a structured space and time to reflect on their teaching through the Searle Fellows Program, a yearlong faculty development program that employs sustained reflective inquiry and project-based learning. Working individually and with peer groups, department colleagues, senior mentors, and faculty development staff, the faculty participants focus on exploring or resolving a relevant learning and 
teaching issue or problem. Not only does this process help faculty reflect on their teaching and student learning, but the projects also help the program staff to assess the participants' learning and sense of improvement and, in turn, to evaluate the program's effectiveness.

\section{Program Overview}

The faculty development program discussed here is a yearlong (eight-month) program for pre-tenure faculty at Northwestern University. The program seeks to provide faculty with the expertise and knowledge to critically assess and solve problems in their courses. To participate in the program, applicants must provide a description of a substantive teaching project related to a course they teach. In most cases, faculty are nominated for the program by deans or department chairs and self-select in or out according to their ability to participate in all program events. Since the program began in 1999, we have had 98 junior faculty from 9 out of 12 of the university's schools.

The program has two main goals: 1) to strengthen the participants' knowledge, understanding, and expertise in learning and teaching; and 2) to help them develop a project that will foster deep student learning (Entwistle, 1997). These projects usually focus on the development of a new course or curriculum, the revision of an existing course or curriculum, or the revision of a key assessment strategy in a course or curriculum.

Participants attend monthly dinner workshops, a two-day retreat led by the teaching center staff, three project group meetings, three or four teaching and learning workshops, and consultation meetings with senior faculty mentors and center staff. Rather than focusing simply on providing strategies, techniques, and tips, the program seeks to foster critical inquiry and professional reflection on teaching (Light \& Cox, 2001).

Throughout the program we emphasized learning theory to promote student-focused, learning-oriented conceptions and approaches to teaching. These approaches aim to facilitate conceptual understanding and change in students rather than simple factual recall (Kember, 1997; Kember \& Kwan, 2000; Prosser \& Trigwell, 1999). They also promote deeper student learning (Entwistle, 1997; Marton \& Booth, 1997; Ramsden, 2003) and improved learning outcomes (Kember \& Gow, 1994; Prosser \& Trigwell, 1999).

In addition, we highlighted core aspects of course design, encouraging our faculty to focus on learning outcomes, teaching methods, and assessments that moved them beyond traditional teacher-focused lectures and assessments. For example, participants learned about Kolb's (1984) Experiential Learning Cycle and student-focused taxonomies, such as Bloom's (1956) Tax- 
onomy of Educational Objectives and Biggs's Structured Observation of Learning Outcomes taxonomy (Biggs \& Collis, 1982), all of which promote critical thinking, active learning, and real-world relevance of course material. Throughout the program, we also publicized the benefits of student-active teaching methods (problem-based learning $[\mathrm{PBL}]$ and inquiry-based learning [IBL], case studies, role playing, small group work, discussion, etc.) and classroom assessment techniques (minute papers, concept maps, short reflections, self- and peer feedback, etc.).

Finally, we encouraged our faculty to have a small group analysis or midterm student focus group conducted in their classes to find out the students' perceptions of what aspects of the course were enhancing and impeding their learning, and to make adjustments accordingly. Along with their projects, these program components motivated our participants to reflect on and assess their development as teachers and, in many cases, to adopt a learning-focused approach to teaching.

\section{Project-Based Learning}

Project-based learning originated in PBL and IBL, two approaches that challenge learners with an ill-defined problem or set of problems and ask them to construct a reasonable solution, either over the duration of a course (PBL: Boud \& Feletti, 2001; Ross, 2001; Schwartz, Mennin, \& Webb, 2001) or in a single lesson or assignment (IBL: Lee, 2004). In both of these approaches, the learners, working individually or in collaborative groups, must be selfdirected and construct knowledge for themselves. In our program, the faculty learner defines the problem to be resolved and tackles it through a process of active inquiry and deep critical thinking. This type of learning is also experiential and relies on doing (Kolb, 1984).

\section{Project Goals and Description}

As they develop their projects, participants are asked to identify learning outcomes, the methods they will use to help students achieve these outcomes, and their plans to assess their students' achievement. They work on their projects for several months, getting feedback from their fellow participants, department colleagues, and the center staff. At the end of the academic year, participants write up their projects ("critical accounts"), which we publish and bind in professional booklets. Participants present their final outcomes to the rest of their cohort and leading university administrators. 


\section{Case Study Analysis}

We offer several program participant cases to illustrate how faculty understood improvement and experienced change in their teaching. We use a model (see Table 14.1) that differentiates three orientations, or categories, of how faculty understand teaching improvement. This model draws on several theoretical frameworks that distinguish teacher-focused/content-oriented and student-focused/learning-oriented teaching (Akerlind, 2003; Kember, 1997; Prosser \& Trigwell, 1999).

\section{TABLE 14.1}

Improving Teaching: How Do Faculty Understand Improvement?

\begin{tabular}{|c|c|c|}
\hline Category & \multicolumn{1}{|c|}{ Improvement Focus } & Key Aspects of Focus \\
\hline $\begin{array}{c}\text { Transmission: } \\
\text { Improving } \\
\text { teaching }\end{array}$ & $\begin{array}{l}\text { - Improve quality/quantity of content } \\
\text { - Improve structure/organization of content }\end{array}$ & \multirow{2}{*}{ Teacher focused } \\
\cline { 2 - 3 } & $\begin{array}{c}\text { Acquire/increase experience of teaching } \\
\text { Expand practical teaching strategies/tips }\end{array}$ & \\
\hline $\begin{array}{c}\text { Acquisition: } \\
\text { Improving } \\
\text { student } \\
\text { acquisition }\end{array}$ & $\begin{array}{c}\text { - Develop teaching strategies that students } \\
\text { perceive as working for them } \\
\text { Develop ways to improve students' acquisi- } \\
\text { tion of course content }\end{array}$ & $\begin{array}{c}\text { Student and teacher } \\
\text { focused }\end{array}$ \\
\hline $\begin{array}{c}\text { Engagement: } \\
\text { Improving } \\
\text { student learning }\end{array}$ & $\begin{array}{c}\text { Develop ways to improve students' concep- } \\
\text { tual understanding }\end{array}$ & $\begin{array}{c}\text { Learning, student, } \\
\text { and teacher focused }\end{array}$ \\
\hline
\end{tabular}

In the first category, faculty view teaching primarily as a means to transmit content and their own knowledge to passively receptive students, a process often referred to as information transmission. Faculty in this category, discussed in Cases 1 and 2, are likely to view improvement in teaching as improvement in the quality, quantity, and organization of the course content, and the way they structure and present this content to their students. The focus is still very much on the instructor and content knowledge, not on assessing whether students are actually learning.

In the second category, faculty begin to take a student-focused view of teaching, concentrating on ways of helping students acquire the course content. Such faculty often view teaching improvement as developing teaching strategies that students view as comfortable or effective. They are focused on 
the student, but they do not yet see teaching as being concerned with student learning as conceptual development or change (see Case 3 ).

At the more sophisticated end of the spectrum are faculty in the third category who regard teaching as facilitating student learning by promoting the students' own construction of knowledge or conceptual understanding. As discussed in Cases 4 and 5, such faculty are likely to view teaching improvement as improving students' achievement of deeper learning outcomes and their engagement in their own learning in a process of conceptual change.

While these views of teaching improvement can be more simply categorized as teacher focused, student focused, and learning focused, respectively, each successive category includes the one before. Thus, learning focused is student focused by definition, but the opposite is not necessarily the case. The following cases span the range of these categories.

\section{nCase 1: Improving Teaching as Improving the Quality of Course Content}

For his project, Professor Gupta sought to revise a large lecture course on macroeconomics. In his opinion, the course had gone "relatively well" in the past but he thought it was too concept-heavy and did not contain enough content that was readily testable by rote learning, a method he relied on in his other courses. Since he considered the material in this course to be "somewhat abstract," he also found it hard to design appropriate assignments. Professor Gupta sought to revise the course by improving his delivery of content so that students would enjoy his presentations and the topics more. He collected new resources, especially PowerPoint and other multimedia, to present to the class, to jazz up the content delivery. As he explained:

Instead of relying entirely on professor-led lectures, I want to rely only almost entirely on professor-led lectures. The change involves adding resources to the syllabus that land on students differently, such as graphics, videos, literature, demonstrations, and expert guests. Too much of these kinds of resources would likely undercut the seriousness of the class, so my goal is to just leaven the spoken word lectures with a sprinkling of other things.

In this case, the instruction is professor-led and the focus is on improving his course content and the organization of the course. One of Professor Gupta's main goals was to learn how to transmit course material more clearly to his students. He did pay some attention to backwards course design-a strategy endorsed frequently in the program. In his final project report, Professor Gupta explained: 
I have tried to think of the course from the back to the front, in the sense of beginning with the kinds of questions I want students to be able to answer on a final exam and then thinking back through the course to be sure they are getting the information they need along the way. I am realizing that this approach is useful for thinking critically about what material I include, emphasize, or skip as I design the syllabus.

Yet the evidence from his critical account suggests that he still focused primarily on improving content delivery rather than developing the skills and learning of his students.

\section{Case 2: Improving Teaching as Improving Instructor Performance}

In his project, Professor Brown redesigned an introductory biology class for nonmajors and had several objectives in mind. He wanted his students to learn about the science of biology, including key terms and concepts. He also wanted to improve his lecturing, better convey his passion for the material and the discipline, and help his students become more comfortable with biology and feel "confident that their time was well-spent." Because he knew that most students signed up for the course because of a "fun" field trip conducted at the end of the term, he felt challenged to "maintain a high level of participation and enthusiasm" about the course material until the field trip.

Professor Brown primarily viewed improving teaching as expanding his knowledge of practical teaching strategies and tips in order to improve his own performance as an instructor. In his course redesign, Professor Brown trimmed what he termed "extraneous material" from his lectures to "liberate lecture time for other activities," including occasional in-class exercises and class presentations. For example, on one occasion, he had his students complete an ungraded, collaborative biology exercise to "change the pace of lecture" and to prepare them for the weekly lab. But when his students did not talk to each other as expected, he abruptly ended the exercise and showed the correct answer using a computer animation, as if the in-class exercise had never been attempted.

Even though Professor Brown was clearly reluctant to lose his sense of authority and control over the class, his introduction of new student-led teaching strategies and activities indicated a growing focus on how students acquire material. In his critical account, he stated that the next time he teaches the course, "I intend to create a before and after survey to better assess changing student beliefs, expectations, and understanding about biology. This information will allow me to better refine the course content." We viewed his goal to 
survey his students about their conceptual understanding of biology as promising and suggestive of someone moving into the transitional phase (discussed next), even though his current goal is "to better refine course content," rather than to promote student learning.

\section{Case 3: Improving Teaching as Developing Teaching Strategies to Improve Student Acquisition of Course Content}

Like many of our faculty participants, Professor Greene joined our program because she had received poor course evaluations and hoped to develop more confidence in her teaching. For her project, Professor Greene revised a large lecture course required for business majors, applying several lessons gleaned from the program. Unlike the first time she taught the course, in which she relied on "traditional" lectures to transmit central theoretical and empirical contributions of organizational theory, with little real-world application, this time she designed the course backwards, beginning with the student learning objectives (Light \& Cox, 2001; McKeachie, 2002). She wanted her students to know more than content; she wanted them to know how to study social phenomena from a scientific perspective and be able to apply those principles and skills to other courses and in their future careers.

Professor Greene then set out to align these new learning objectives with her assessments and teaching methods. She structured the course around recent dramatic events (such as Hurricane Katrina) to make the course content and theory relevant to her students. She also employed ungraded, interactive short games and exercises to assess learning, to help her students acquire course content, and to give extensive feedback. For example, she used a common classroom assessment technique, the minute paper, to see if her students were grasping key concepts (Angelo \& Cross, 1993). She felt rewarded when, in focus groups, her students later expressed their appreciation for these exercises; these assessments showed she cared about their learning.

Professor Greene falls into the transitional category, along with many other participants in our program. She adopted backwards course design and several active learning techniques used to make the course more relevant to her students, indicating that she was taking a much stronger student-focused approach to teaching. At the same time, her frequently expressed concerns about her teaching prowess, particularly whether her students would "like" her teaching methods, suggest that she was still not focusing on enhancing her students' learning. Nevertheless, she did start to concentrate on engaging her students more effectively and, as she gains confidence in her teaching, that focus may evolve into improving her students' conceptual understanding. 


\section{Case 4: Improving Teaching as Developing Students' Conceptual Understanding}

For his project, Professor Lee developed a new assessment for a required introductory engineering course. As he explained in his critical account, "The stereotypical view of Engineering as 'problem solving' and Science as 'finding problems to solve' strongly persists in the students' mind and, in a larger context, society." His learning objectives for the course, then, were to enable students to connect their subject matter to the underlying science, to analyze complex material scientifically, and to assess their peers' and their own work. To help his students meet these objectives, Professor Lee designed a weekly "game quiz" that offered his students both formative and summative assessment, introduced them to complex material, and lowered the professor-student social barriers. As he has students playing in groups, he also sought to reduce the negative sense of competition often found in engineering classes.

In his game quiz, Professor Lee randomly assigned students to small groups. Each week, one group (the "Q-group") would develop a "nugget question" that would "encapsulate the essence of the topic of the week" and have multiple respectable answers in order to promote discussion. Group members assessed their own and each other's participation, and Professor Lee graded the group's question on its adherence to several criteria (relevance to topic, design, and clarity). The other groups would discuss the problem and submit a written solution or opinion. In class, the Q-group facilitated discussion of the various solutions and (with the assistance of Professor Lee) agreed on the best one. In the process, all of the students assessed their own understanding of the material in a formative way. According to Professor Lee, "The proposed activity generated a fun atmosphere for open discussion that should lead to a deeper understanding of the topics ... and enhance the group learning process."

For Professor Lee, growth as a teacher meant learning to develop his students' conceptual understanding of the course content, even if it meant relinquishing some control to his students. He sought to engage his students deeply in their own learning by having them wrestle with difficult concepts, apply the concepts in the form of a question, and know the concepts well enough to help the other students weigh the merits of various solutions-all the while assessing their own and each other's performance.

\section{Case 5: Improving Teaching as Developing Ways to Promote Conceptual Change}

For her project, Professor Kung redesigned a required nèws writing course to help students learn how to practice journalism in a way that combines media 
forms (broadcast, magazine, newspaper, and new media). In her course revision, she focused on promoting problem solving and active learning and on refining her students' news editing and news writing skills. In addition, she gave her students power and voice in the classroom. As she explained, "The focus of the class needed to shift from an 'I lecture, now you write' approach in the bi-weekly three-hour lab sections to a more convivial newsroom atmosphere with the instructor acting as coach and editor."

In the past, Professor Kung had simply assigned stories for her students to write, which she would then critique. In the revised course, students were expected to generate their own original story ideas and sources and to take turns leading the class in making progress reports, providing updates, and reporting problems and solutions. They were also required to give each other feedback, publish their stories publicly on the web, and discuss their projects at the end of the term in a public student forum.

For Professor Kung, improvement in her teaching meant her students finding their own voices as journalists and changing their conception of journalism. In her critical account, she described what she termed the "profound" learning outcomes of the class: "By creating a newsroom atmosphere and demanding a professional level of work that will be published and seen on the university's Web site, the results are learning outcomes that move into the personal, intellectual, and social realms."

She purposely released control of the course so that her students could share responsibility for what they learned in the class. By actively engaging her students in the news creation process, the course mirrored the real world of journalism. By emphasizing relevance and student-led learning, she illustrated a holistic, learning-focused approach to teaching.

\section{Analysis of Critical Accounts}

We analyzed 41 critical accounts (drawn from the last three years of the program) more specifically in terms of the model described earlier. We found that nine participants' views of improvement in teaching could be construed primarily as content oriented and teaching focused. As described in Cases 1 and 2, participants in this category often expressed interest in developing teaching strategies or accruing new teaching tips in order to transmit course content more effectively or to improve their performance as a teacher, Eighteen participants fell into the transitional, or student-focused, category, as discussed in Case 3, in which instructors seek ways to improve students' acquisition of course content. Finally, 14 participants could be categorized at the highest 
conceptual level of enhancing student learning by promoting conceptual understanding and conceptual change, as described in Cases 4 and 5.

The following passages from the critical accounts represent commonly expressed views of teaching improvement that the participants developed by the end of the program, and this improvement definitely leans toward the student- and learning-focused end of the spectrum:

Now my goal is to engage students and create a more dynamic environment for deeper learning... thus my focus now will be on critical thinking and problem-solving, rather than disseminating as much surface-learning material as I can. (Political science)

I feel particularly strongly about [using] case studies because they enable students who are thoughtful and deep learners an opportunity to excel. Superficial and strategic learners would most likely focus on answering the questions on the assignment sheet, whereas deep learners may try different approaches and focus on the underlying problem and on providing a set of recommendations that are practical and substantiated with thorough analysis. (Engineering)

One of the most welcome results of the conceptual changes underlying a new conception of myself as a facilitator ... has been a new vision of the large lecture course. Instead of conceiving large lectures as something categorically different from small seminars, I now view both learning environments as situations suitable for active interaction between instructor and students and for small, peer-referenced learning as well as instructor-driven learning. (Foreign literature)

Before I would tell the students they need to know this or that but now it's more "no, you don't need to know that." I am more selective in what material is important for the students to read. I get them to focus on the most important materials, get them to.understand it. I focus on deep learning more than absorbing all the material. (Sociology)

\section{General Discussion}

Many of our faculty participants, typically short on teaching experience, enter our program holding the teacher-focused, transmission-focused view of teaching. Not only did our program foster their critical reflection, but it also launched them into a sustained inquiry into their teaching as they created or redesigned courses. Although the case studies represent each phase of the 
transmission engagement model of faculty improvement, very few participants stayed firmly entrenched in the transmission mode. The faculty who started there, like those described in Cases 1 and 2, came to find value in more student-focused teaching methods, albeit reluctantly at times. These findings echo Akerlind's (2003) contention that faculty who view growth in their teaching as primarily improving the quality and organization of content may be less open to more far-reaching change than those who define growth as improving student learning outcomes.

While many of our participants arguably fell into the transitional category-viewing improvement as developing teaching strategies that students perceive as working or as helping them to simply acquire concepts-a significant number clearly focused on deep learning as opposed to surface learning. As McKenzie (2002) suggests, faculty who are exposed to a range of teaching modes, allowing them to see the differences between teacher-focused, student-focused, and fully learning-focused modes, are more likely to develop sophisticated conceptions of teaching. Yet even the participants who adopted student-focused approaches did not necessarily achieve the highest, most sophisticated level of understanding of teaching growth-that is, viewing improvement as promoting deep conceptual development and change in their students. This may be due in part to faculty reluctance to adopt a more learner-centered orientation, whether from a lack of teaching experience, fear of deviating from traditional teaching methods, or even a low priority placed on good teaching (McAlpine \& Weston, 2000).

Overall, requiring our faculty participants to conceptualize and implement a sustained, yearlong teaching project allows them to structure their experience of teaching using key theoretical frameworks. The project provides them with an area of focused inquiry into their teaching, with direct relevance and application, a crucial component of PBL (Boud \& Feletti, 2001). Together with the written critical account, the project helps the participants reflect on and clarify their teaching and learning objectives and assess their overall practice. Moreover, we have found that the model described here allows us to better interpret the projects and critical accounts, helping us cultivate a deeper understanding of how our faculty members think about improvement. Clearly, our participants can and do improve within a category, but we use what we learn from these projects and accounts to develop our program so that more of our faculty will come to view improvement as developing learner-focused teaching and promoting students' conceptual change. 


\section{Author Note}

All names and disciplines discussed in the case studies have been changed to ensure confidentiality.

\section{References}

Akerlind, G. S. (2003, October). Growing and developing as a university teacherVariation in meaning. Studies in Higher Education, 28(4), 375-390.

Angelo, T. A., \& Cross, K. P. (1993). Classroom assessment techniques: A handbook for college teachers (2nd ed.). San Francisco, CA: Jossey-Bass.

Biggs, J. B., \& Collis, K. F. (1982). Evaluating the quality of learning: The SOLO taxonomy. San Diego, CA: Academic Press.

Bloom, B. S. (Ed.). (1956). Taxonomy of educational objectives, handbook 1: Cognitive domain. New York, NY: Longman.

Boice, R. (1992). The new faculty member: Supporting and fostering professional development. San Francisco, CA: Jossey-Bass.

Boud, D., \& Feletti, G. (Eds.). (2001). The challenge of problem-based learning (2nd ed.). London, UK: Kogan Page.

Brew, A. (2003, May). Teaching and research: New relationships and their implications for inquiry-based teaching and learning in higher education. Higher Education Research and Development, 22(1), 3-18.

Entwistle, N. (1997). Contrasting perspectives on learning. In F. Marton, D. Hounsell, \& N. Entwistle (Eds.), The experience of learning (pp. 3-22). Edinburgh, Scotland: Scottish Academic Press.

Hattie, J., \& Marsh, H.W. (1996, Winter). The relationship between research and teaching: A meta-analysis. Review of Educational Research, 66(4), 507-542.

Kember, D. (1997, September). A reconceptualisation of the research into university academics' conceptions of teaching. Learning and Instruction, 7(3), 255-275.

Kember, D., \& Gow, L. (1994, January/February). Orientations to teaching and their effect on the quality of student learning. Journal of Higher Education, 65(1), 58-74.

Kember, D., \& Kwan, K.-P. (2000, September). Lecturers' approaches to teaching and their relationship to conceptions of good teaching. Instructional Science, 28(5-6), 469-490.

Kolb, D. A. (1984). Experiential learning: Experience as the source of learning and development. Upper Saddle River, NJ: Prentice-Hall. 
Lee, V.S. (Ed.). (2004). Teaching and learning through inquiry: A guidebook for institutions and instructors. Sterling, VA: Stylus.

Light, G., \& Cox R. (2001). Learning and teaching in higher education: The reflective professional. Thousand Oaks, CA: Sage.

Marton, F., \& Booth, S. (1997). Learning and awareness. Mahwah, NJ: Lawrence Erlbaum.

McAlpine, L., \& Weston C. (2000, September). Reflection: Issues related to improving professors' teaching and students' learning. Instructional Science, 28(5-6), 363-385.

McKeachie, W. J. (2002). McKeachie's teaching tips: Strategies, research, and theory for college and university teachers (11th ed.). Boston, MA: Houghton Mifflin.

McKenzie, J. (2002). Variation and relevance structures for university teachers' learning: Bringing about change in ways of experiencing teaching. In A. Goody, J. Herrington, \& M. Northcote (Eds.), Annual International Conference of Higher Education Research and Development Society of Australasia (pp. 434-441). Perth, Australia: Higher Education Research and Development Society of Australasia.

Mullen, C. A., \& Forbes, S. A. (2000, April). Untenured faculty: Issues of transition, adjustment and mentorship. Mentoring and Tutoring, 8(1), 31-46.

Palmer, P. J. (1998). The courage to teach: Exploring the inner landscape of a teacher's life. San Francisco, CA: Jossey-Bass.

Prosser, M., \& Trigwell, K. (1999). Understanding learning and teaching: The experience in higher education. Buckingham, UK: Society for Research into Higher Education \& Open University Press.

Ramsden, P. (2003). Learning to teach in higher education. New York, NY: RoutledgeFalmer.

Ross, B. (2001). Towards a framework for problem-based curricula. In D. Boud \& G. Feletti (Eds.), The challenge of problem-based learning (2nd ed., pp. 28-35). London, UK: Kogan Page.

Schön, D. A. (1983). The reflective practitioner: How professionals think in action. New York, NY: Basic Books.

Schwartz, P., Mennin, S., \& Webb, G. (Eds.). (2001). Problem-based learning: Case studies, experience and practice. London, UK: Kogan Page.

Wolverton, M. (1998, Fall). Treading the tenure-track tightrope: Finding balance between research excellence and quality teaching. Innovative Higher Education, 23(1), 61-79. 